NBER WORKING PAPER SERIES

\title{
AN ECONOMIC ANALYSIS OF PLATFORM SHARING
}

\author{
Arghya Ghosh \\ Hodaka Morita \\ Working Paper 13058 \\ http://www.nber.org/papers/w13058 \\ NATIONAL BUREAU OF ECONOMIC RESEARCH \\ 1050 Massachusetts Avenue \\ Cambridge, MA 02138 \\ April 2007
}

We wish to thank Reiko Aoki, George Baker, Hans Gottinger, Hideshi Itoh (the editor), an anonymous referee, and participants at the 20th Annual TRIO conference for insightful comments, and Jonathan Lim for his excellent research assistance. Morita is grateful for support from the Australian Research Council. The views expressed herein are those of the author(s) and do not necessarily reflect the views of the National Bureau of Economic Research.

(C) 2007 by Arghya Ghosh and Hodaka Morita. All rights reserved. Short sections of text, not to exceed two paragraphs, may be quoted without explicit permission provided that full credit, including @ notice, is given to the source. 
An Economic Analysis of Platform Sharing

Arghya Ghosh and Hodaka Morita

NBER Working Paper No. 13058

April 2007

JEL No. D40,L10,L40,M20

\begin{abstract}
We explore the managerial implications and economic consequences of platform sharing under models of horizontal and vertical product differentiation. By using a common platform across different products, firms can save on fixed costs for platform development. At the same time, platform sharing imposes restrictions on firms' ability to differentiate their products, and this reduces their profitability. It might appear that platform sharing across firms makes consumers worse off because firms cooperate in their product development processes to maximize their joint profit. We find, however, that platform sharing across firms benefits consumers in our framework because it intensifies competition in our horizontal differentiation model, and because it increases the quality of the lower-end product in our vertical differentiation model. We also show new channels through which a merger makes consumers worse off in the presence of platform sharing.
\end{abstract}

Arghya Ghosh

University of New South Wales

School of Economics

Sydney NSW 2052

Australia

a.ghosh@unsw.edu.au

Hodaka Morita

School of Economics

University of New South Wales

Sydney, NSW 2052

Australia

h.morita@unsw.edu.au 


\section{Introduction}

Product platforms, which are component and subsystem assets shared across a family of products, ${ }^{1}$ have recently attracted increasing attention in the product development/design literature (see e.g. Meyer and Lehnerd, 1997; Nobeoka and Cusumano, 1997; Robertson and Ulrich, 1998). Robertson and Ulrich (1998) conceptually articulated the trade-off that firms face when they share a common platform across multiple products. On the one hand, by sharing components and production processes across products, firms can develop differentiated products efficiently. That is, platform sharing reduces product development cost and time because parts and assembly processes developed for one model do not have to be developed and tested for the others. On the other hand, since components and production processes are important factors in determining the nature of products, platform sharing reduces the distinctiveness of products, which is valuable in the marketplace. Given this important trade-off, Robertson and Ulrich proposed the platform-planning process through which firms can achieve an optimal balance of commonality and distinctiveness.

Platform sharing has become common in the automobile industry; an automobile platform means the core framework of cars which includes the floorpan, drive train, and axles. An automobile manufacturer often uses a common platform for different products with similar quality levels. For example, Mitsubishi shares a common platform between its Endeavour and Galant, and Honda shares a common platform between its CR-V and Civic. ${ }^{2}$ A common platform can also be shared across manufacturers. Renault and Nissan have developed a common platform for the Nissan Micra and the Renault Clio, and they plan to reduce the number of platforms they use to 10 in 2010 from the 34 they had in 2000 (see e.g. Tierney et al., 2000; Bremner et al., 2004). See also Szczesny (2003) for platform sharing between Ford Motor and Mazda. These are examples of platform sharing across horizontally differentiated products within a firm and across firms.

An automobile manufacturer can also share a common platform across multiple products with different quality levels. For example, Toyota uses a common platform for its Landcruiser

\footnotetext{
${ }^{1}$ This definition of product platforms is from Krishnan and Gupta (2001). Several authors have offered different definitions. For example, Robertson and Ulrich (1998) defined a product platform as the collection of assets that are shared by a set of products.

${ }^{2}$ Mitsubishi's Endeavour and Galant are in a similar price range, where the former is an SUV while the latter is a sedan. Honda CR-V and Civic are also in a similar price range, where the former is an SUV while the latter is a small sedan and hatch-back. See Rechtin and Kranz (2003) and Anonymous (2006).
} 
and Lexus LX 470, and Honda uses a common platform for its CR-V and Acura RDX. ${ }^{3}$ As an example of platform sharing across firms, Porshe and Volkswagen use a common platform for Porshe's Cayenne and Volkswagen's Touareg, ${ }^{4}$ where the former is more luxurious than the latter. These are examples of platform sharing across vertically differentiated products within a firm and across firms.

This paper explores the managerial implications and economic consequences of platform sharing under product differentiation models. Motivated by examples in the automobile industry as mentioned above, we consider platform sharing under horizontal product differentiation and platform sharing under vertical product differentiation, and compare the economic consequences of platform sharing under the two setups.

In Section 2 we incorporate platform sharing into a standard model of horizontal product differentiation, due to Dixit (1979) and Singh and Vives (1984), where we consider the monopoly case and the duopoly case. In the monopoly case, one firm produces two differentiated products 1 and 2, while in the duopoly case each firm $i(=1,2)$ produces product $i$. Demand side of the model is characterized by the representative consumer who prefers product variety. Platform sharing reduces the degree of product differentiation, which in turn reduces the representative consumer's willingness to pay. Because of this effect, platform sharing makes consumers worse off in the monopoly case. However, we find that platform sharing makes consumers better off in the duopoly case because platform sharing intensifies competition between the two firms by reducing the degree of differentiation in their products. Firms can still choose to share a common platform in order to save on their fixed costs for developing platforms. We then explore welfare consequences of horizontal mergers in our framework and demonstrate a new channel through which horizontal mergers could hurt consumers.

In Section 3 we explore the connection between platform sharing and vertical product differentiation under a standard framework of product-line pricing (Mussa and Rosen, 1978), where we focus on the two-type consumer case consisting of high-valuation consumers and low-valuation consumers. On the production side, we again consider monopoly as well as duopoly, and compare the two. In the case of monopoly, a single firm can produce a highquality product ( $H$-product) and a low-quality product ( $L$-product), while in the case of

\footnotetext{
${ }^{3}$ Lexus LX 470 is more luxurious than Toyota Landcruiser, and Acura RDX is more luxurious than Honda CR-V. See Anonymous (2006) and Rechtin and Kranz (2003).

${ }^{4}$ We have confirmed this by our written inquiry to Volkswagen.
} 
duopoly one firm can produce a high-quality product and the other firm can produce a low-quality product. Platform sharing between an $H$-product and an $L$-product imposes restrictions on firm's abilities to differentiate the quality of products, which in turn increases the amount of surplus captured by consumers in the equilibrium. In other words, platform sharing increases the consumer surplus because its benefit of fixed cost savings has to be shared between producers and consumers. We find that a platform is more likely to be shared in the duopoly case than in the monopoly case, and we demonstrate a new channel through which the merger between $H$-firm and $L$-firm could make consumers worse off; that is, the merger makes platform sharing less attractive for producers, and this can reduce the consumer surplus because platform sharing benefits consumers.

We will then conclude in Section 4 by discussing relationships between platform sharing under horizontal product differentiation and that under vertical product differentiation.

The present paper is related to the previous analyses on cooperative research and development $(\mathrm{R} \& \mathrm{D})$ and research joint ventures $(\mathrm{RJVs})$, given that platform sharing can be regarded as an example of cooperative R\&D and RJVs (see Katz, 1986; d'Aspremont and Jacquemin, 1988; Kamien et al., 1992; Suzumura, 1992; Motta, 1992; Choi, 1993, among others). These previous papers, however, have not considered cases in which cooperative R\&D and RJVs affect product characteristics.

A few previous papers have considered models that incorporate product platforms in product differentiation models. Krishnan and Gupta (2001) incorporated product platforms into a model of vertical product differentiation in which a firm chooses whether or not to introduce a common platform across two separate products, and demonstrated that using a common platform tends to result in the overdesign of low-end products (or the underdesign of high-end products) in the firm's product family. Ghosh and Morita (2006) considered a differentiated duopoly model in which two firms can share a common platform to save on their procurement costs from suppliers at the expense of the reduction in their horizontal product differentiation. Ghosh and Morita (2006) also offered an informal discussion on a monopoly analysis of platform sharing under vertical product differentiation. ${ }^{5}$

The present paper's contribution is to offer more comprehensive and systematic analyses of platform sharing by conducting both monopoly and duopoly analysis of platform sharing

\footnotetext{
${ }^{5}$ See also Lambertini, Poddar, and Sasaki $(2002,2003)$, who considered models of RJVs in which RJVs between firms reduce the degree of their product differentiation, and explored the effects of forming an RJV on the sustainability of implicit price collusion.
} 
under horizontal product differentiation and that under vertical product differentiation. As mentioned above, Krishnan and Gupta (2001) focused on a monopolist's platform-sharing decision under vertical product differentiation, while Ghosh and Morita (2006) focused on platform sharing under horizontal product differentiation in the duopoly case with an informal discussion on a monopoly analysis of platform sharing under vertical product differentiation. Through our comprehensive and systematic analyses of platform sharing, we explore effects of mergers in the presence of platform sharing, and compare welfare consequences of platform sharing under horizontal product differentiation and that under vertical product differentiation.

\section{Platform sharing under horizontal product differen- tiation}

In this section we incorporate platform sharing into a standard model of horizontal product differentiation, due to Dixit (1979) and Singh and Vives (1984). On the production side, we consider and compare monopoly and duopoly. In the monopoly case, a single firm produces two differentiated products, while in the duopoly case, each firm produces one product.

\section{$2.1 \quad$ Monopoly}

\subsubsection{The Model}

Consider a monopolist who produces two products, 1 and 2. Let $p_{i}$ and $q_{i}$ denote the price and quantity of product $i(=1,2)$. There is a continuum of consumers with identical preferences, and the representative consumer's utility function is given by $U\left(q_{1}, q_{2}\right)=a\left(q_{1}+\right.$ $\left.q_{2}\right)-\left(q_{1}^{2}+2 b q_{1} q_{2}+q_{2}^{2}\right) / 2$, where $a>0$ and $b \in(0,1)$. The parameter $b$ captures the degree of differentiation between the two products, where the degree of product differentiation decreases as $b$ increases. The representative consumer maximizes $U\left(q_{1}, q_{2}\right)-p_{1} q_{1}-p_{2} q_{2}$ which yields linear inverse demands

$$
p_{i}=a-q_{i}-b q_{j}, \quad i, j \in\{1,2\} ; i \neq j .
$$

Inverting the inverse demand system yields the direct demands:

$$
q_{i}=\frac{(1-b) a-p_{i}+b p_{j}}{1-b^{2}}, \quad i, j \in\{1,2\} ; i \neq j .
$$


The monopolist's cost for producing $q_{i}$ units of product $i(=1,2)$ is $c_{i} q_{i}+F_{i}$ where $c_{i}$ and $F_{i}$ respectively denote the constant marginal cost and the fixed cost for production. Without loss of generality we normalize $c_{1}=c_{2}=0$.

We incorporate the option of platform sharing in the following way: Assume that $F_{1}=$ $F_{2}=F(>0)$ if the monopolist uses different platforms for the two products, while $F_{1}=F_{2}=$ $(1-s) F$ if it uses a common platform for both products, where $s \in(0,1)$ captures the degree of cost saving. That is, by sharing a platform, the monopolist saves $2[F-(1-s) F]=2 s F$ of its total fixed costs. On the other hand, the monopolist loses some product differentiation by sharing a platform. We capture this effect by assuming that $b=b_{0}$ if the monopolist does not share a platform, while $b=b_{0}+x$ if it does share a platform, where $b_{0} \in(0,1)$ and $x \in\left(0,1-b_{0}\right) .{ }^{6}$ That is, under platform sharing, the degree of product differentiation decreases by $x$.

We consider the two-stage game described below:

[Stage 1] The monopolist decides whether or not to use a common platform for the two products, 1 and 2. If the monopolist does not share a platform, then $F_{1}=F_{2}=F$ and $b=b_{0}$, while $F_{1}=F_{2}=(1-s) F$ and $b=b_{0}+x$ if it does share a platform.

[Stage 2] The monopolist chooses $\left(p_{1}, p_{2}\right)$ to maximize its profit.

\subsubsection{Analysis of the monopoly case}

The game described above has two Stage 2 subgames. One is the subgame in which the monopolist shared a platform at Stage 1, while the other is the one in which it did not share a platform. We call the former subgame a platform-sharing subgame, and the latter, a nonplatform-sharing subgame. Throughout the analysis we assume $F<\min \left\{\frac{a^{2}\left(1-b_{0}-x\right)}{4\left(1+b_{0}+x\right)}, \frac{a^{2}\left(1-b_{0}\right)}{8\left(1+b_{0}\right)}\right\}$, which ensures that the fixed cost for production is low enough for the monopolist to sell a strictly positive amount of each product $i(=1,2)$ in the equilibrium of each subgame.

At stage 2 , the monopolist chooses $p_{1}$ and $p_{2}$ to maximize its stage 2 profit, which is $p_{1} q_{1}+p_{2} q_{2} \equiv \frac{p_{1}\left((1-b) a-p_{1}+b p_{2}\right)+p_{2}\left((1-b) a-p_{2}+b p_{1}\right)}{1-b^{2}}$. Let $p_{i}^{m}(b)$ and $q_{i}^{m}(b)$ denote product $i$ 's price and quantity, respectively, in the equilibrium of the stage 2 subgame characterized by differentiation parameter $b$ (recall that $b=b_{0}+x$ in the platform-sharing subgame while

\footnotetext{
${ }^{6}$ This set up for platform sharing under horizontal product differentiation was employed by our previous model analyzed in Ghosh and Morita (2006). See also Lin and Saggi (2002) for a related modelling choice in their analysis of the relationship between process and product R\&D.
} 
$b=b_{0}$ in the non-platform-sharing subgame). We find:

$$
\begin{array}{r}
p_{1}^{m}(b)=p_{2}^{m}(b)=\frac{a}{2} \equiv p^{m}(b), \\
q_{1}^{m}(b)=q_{2}^{m}(b)=\frac{a}{2(1+b)} \equiv q^{m}(b), \\
p_{1}^{m}(b) q_{1}^{m}(b)+p_{2}^{m}(b) q_{2}^{m}(b)=\frac{a^{2}}{2(1+b)} \equiv \pi^{m}(b),
\end{array}
$$

where $\pi^{m}(b)$ denotes the monopolist's stage 2 profit in the equilibrium.

At stage 1 , the monopolist anticipates that its overall profit will be $\pi_{N P} \equiv \pi^{m}\left(b_{0}\right)-2 F$ if it does not share a platform, and $\pi_{P S} \equiv \pi^{m}\left(b_{0}+x\right)-2(1-s) F$ if it does share a platform. Hence the monopolist chooses to share a platform if and only if $\pi_{P S} \geq \pi_{N P}$, which is equivalent to

$$
2 s F \geq \pi^{m}\left(b_{0}\right)-\pi^{m}\left(b_{0}+x\right) .
$$

We are now ready to present our first result.

Proposition 1: There exists a function $x^{m}(s)$ such that the monopolist shares a platform in the equilibrium if and only if $x \leq x^{m}(s)$, where $x^{m}(s)$ is strictly increasing in $s$ and $x^{m}(s) \in\left(0,1-b_{0}\right)$ for all $s \in(0,1)$.

Proposition 1 tells us that the monopolist chooses to share a platform when the loss of product differentiation due to platform sharing, captured by $x$, is relatively small. Under platform sharing, a lower degree of product differentiation between products 1 and 2 reduces the representative consumer's willingness to pay because he/she prefers product variety. The lower willingness to pay, in turn, reduces the monopolist's profitability. This disadvantage of platform sharing is represented by the RHS of inequality (3), $\pi^{m}\left(b_{0}\right)-\pi^{m}\left(b_{0}+x\right)$. We have that the monopolist's stage 2 profit $\pi^{m}(b)$ is strictly decreasing in $b$, given that the degree of product differentiation decreases as $b$ increases in this model. Hence the disadvantage is increasing in $x$, while the fixed cost saving due to platform sharing, captured by $2 s F$ in the LHS of inequality (3), is not affected by $x$. The result is that the monopolist chooses to share a platform if $x$ is relatively small, where the threshold $x^{m}(s)$ is strictly increasing in $s$. That is, the monopolist is more likely to share a platform as the degree of fixed-cost savings due to platform sharing (captured by $s$ ) increases.

Next we analyze the welfare consequences of platform sharing. 
Proposition 2: Let $C S_{P S}\left(C S_{N P}\right)$ denote the consumer surplus in the equilibrium of the platform-sharing (non-platform-sharing) subgame, and define $T S_{P S}\left(T S_{N P}\right)$ analogously for the total surplus. Then

(i) $C S_{P S}<C S_{N P}$ holds for all $x \in\left(0,1-b_{0}\right)$.

(ii) There exists a function $\tilde{x}(s)$ such that $T S_{P S}>T S_{N P}$ holds if and only if $x<\tilde{x}(s)$, where $\tilde{x}(s) \in\left(0, x^{m}(s)\right)$ for all $s \in(0,1)$.

As mentioned above, platform sharing reduces the representative consumer's willingness to pay, and this reduces the consumer surplus as well as the monopolist's stage 2 profit. Hence the consumer surplus is lower under the platform-sharing subgame for all $x$. This negative impact to consumers is not taken into account when the monopolist, who can benefit from platform sharing through fixed-cost savings, determines whether or not to share a platform. If $x<\tilde{x}(s)$, the benefit of platform sharing to the monopolist is greater than its negative externality to consumers so that platform sharing increases the total surplus. While, if $\tilde{x}(s)<x<x^{m}(s)$, the monopolist still shares a platform but its benefit to the monopolist is dominated by its negative impact to consumers so that platform sharing reduces the total surplus.

\subsection{Duopoly}

\subsubsection{The Model}

We consider the case of duopoly under the demand and the cost structures that are the same as in the monopoly case. The only difference is that now there are two firms, firms 1 and 2, where each firm $i(=1,2)$ produces product $i$.

We consider the two-stage game described below:

[Stage 1] Firms 1 and 2 jointly decide whether or not to use a common platform for their products. If they do not share a platform, then $F_{1}=F_{2}=F$ and $b=b_{0}$, while $F_{1}=F_{2}=$ $(1-s) F$ and $b=b_{0}+x$ if they do share a platform.

[Stage 2] Each firm $i$ chooses $p_{i}$ to maximize its own profit, taking $p_{j}$ as given.

\subsubsection{Analysis of the duopoly case}

As in the monopoly case, the stage 2 subgame in which the two firms shared (did not share) a platform at stage 1 is called platform-sharing (non-platform-sharing) subgame. Throughout 
the analysis we assume $F<\min \left\{\frac{a^{2}\left(1-b_{0}\right)}{\left(2-b_{0}\right)^{2}\left(1+b_{0}\right)}, \frac{a^{2}\left(1-b_{0}-x\right)}{(1-s)\left(2-b_{0}-x\right)^{2}\left(1+b_{0}+x\right)}\right\}$, which ensures that the fixed cost for production is low enough for each firm $i$ to sell a strictly positive amount of product $i$ in the equilibrium of each subgame.

Each stage 2 subgame has a unique and symmetric equilibrium. Let $p_{i}^{d}(b), q_{i}^{d}(b)$ and $\pi_{i}^{d}(b)$ respectively denote firm $i$ 's price, quantity, and profit of firm $i$ in the equilibrium of the stage 2 subgame characterized by differentiation parameter $b$ (recall that $b=b_{0}+x$ in the platform-sharing subgame while $b=b_{0}$ in the non-platform-sharing subgame). We find:

$$
\begin{array}{r}
p_{1}^{d}(b)=p_{2}^{d}(b)=\frac{a(1-b)}{2-b} \equiv p^{d}(b), \\
q_{1}^{d}(b)=q_{2}^{d}(b)=\frac{a}{(2-b)(1+b)} \equiv q^{d}(b), \\
\pi_{1}^{d}(b)=\pi_{2}^{d}(b)=\frac{a^{2}(1-b)}{(2-b)^{2}(1+b)} \equiv \pi^{d}(b) .
\end{array}
$$

At stage 1, each firm $i$ anticipates that its overall profit will be $\pi_{N P} \equiv \pi^{d}\left(b_{0}\right)-F$ if the two firms do not share a common platform, and $\pi_{P S}=\pi^{d}\left(b_{0}+x\right)-(1-s) F$ if they do share a platform. Hence the two firms choose to share a platform if and only if $\pi_{P S} \geq \pi_{N P}$, which is equivalent to

$$
s F \geq \pi^{d}\left(b_{0}\right)-\pi^{d}\left(b_{0}+x\right) .
$$

Proposition 3 below identifies the condition in which this inequality holds.

Proposition 3: There exists a function $x^{d}(s)$ such that firms 1 and 2 share a common platform in the equilibrium if and only if $x \leq x^{d}(s)$, where $x^{d}(s)$ is strictly increasing in $s$ and $x^{d}(s) \in\left(0,1-b_{0}\right)$ for all $s \in(0,1)$.

As in the monopoly case, platform sharing reduces the degree of product differentiation between firms 1 and 2, which decreases their profitability by reducing the representative consumer's willingness to pay. Equally important is that in the duopoly case, the lower degree of product differentiation intensifies the competition between the two firms, which further reduces their profitability. The result is that firms 1 and 2 choose to share a common platform if $x$, the loss of product differentiation due to platform sharing, is relatively small. The threshold $x^{d}(s)$ is strictly increasing in $s$, the degree of fixed-cost savings due to platform sharing. 
Next we analyze the welfare consequences of platform sharing.

Proposition 4: Let $C S_{P S}\left(C S_{N P}\right)$ denote the consumer surplus in the equilibrium of the platform-sharing (non-platform-sharing) subgame, and define $T S_{P S}\left(T S_{N P}\right)$ analogously for the total surplus. Then

(i) $C S_{P S}>C S_{N P}$ holds for all $x \in\left(0,1-b_{0}\right)$.

(ii) There exists a function $\hat{x}(s)$ such that $T S_{P S}>T S_{N P}$ holds if and only if $x<\hat{x}(s)$, where $\hat{x}(s) \in\left(x^{d}(s), 1-b_{0}\right)$ for all $s \in(0,1)$.

In the monopoly case, we found in Proposition 2 that platform sharing reduces the consumer surplus because it reduces product variety, which consumers prefer. In contrast, Proposition 4 tells us that platform sharing increases the consumer surplus in the duopoly case. This is because the lower degree of product differentiation intensifies the competition between the two firms, and this positive effect on consumers dominates the negative effect associated with lower product variety. Regarding the total surplus, platform sharing increases the total surplus for all $x \in\left(0, x^{d}(s)\right]$ because platform sharing increases the two firms' joint profit whenever they choose to share a platform. In fact, the threshold $\hat{x}(s)$ is greater than $x^{d}(s)$, because the higher consumer surplus dominates the lower profits of the firms when $x^{d}(s)<x<\hat{x}(s)$.

\subsection{Comparison}

Finally, we compare the monopoly case and the duopoly case, and discuss the welfare consequences of a merger in our framework.

Proposition 5: A platform is more likely to be shared in the monopoly case than in the duopoly case. More precisely, $x^{d}(s)<x^{m}(s)$ holds.

As mentioned earlier, platform sharing in this model reduces the representative consumer's willingness to pay in the monopoly case as well as in the duopoly case. Furthermore, in the duopoly case, platform sharing intensifies the competition between the two firms. Because of the latter effect, the disadvantage of platform sharing for firms is greater in the duopoly case than in the monopoly case, while the advantage of platform sharing (fixed-cost saving) is the same across the two cases. Hence, platform is more likely to be shared in the monopoly case as stated in the proposition. 
Now suppose $x^{d}(s)<x<x^{m}(s)$ holds so that a platform is shared only in the monopoly case, and suppose that firms 1 and 2 merge to become a monopolist. In this parameter range, the horizontal merger makes consumers worse off in two ways. On the one hand, the merger eliminates competition between the two firms, which hurts consumers by raising prices. In addition to this standard effect, the merger induces the merged firm to share a platform, which makes consumers worse off by reducing product variety. By capturing the connection between platform sharing and horizontal product differentiation, our analysis shows a new channel through which mergers could hurt consumers.

\section{Platform sharing under vertical product differentia- tion}

In this section, we explore the connection between platform sharing and vertical product differentiation under a standard framework of product-line pricing (Mussa and Rosen, 1978), where we focus on the two-type consumer case. ${ }^{7}$ On the production side, we consider and compare monopoly and duopoly. In the case of monopoly, a single firm can produce a highquality product and a low-quality product, while in the case of duopoly one firm can produce a high-quality product and the other firm can produce a low-quality product.

\subsection{Monopoly case}

\subsubsection{The Model}

Consider a monopolist that faces two groups of consumers, and which can produce output of two levels of quality: a high-quality product ( $H$-product) and a low-quality product ( $L$ product). The quality of the product is in part determined by the quality of the platform. In particular, assume that the quality of $H$-product is given by $Q_{H}=H+x \equiv Q_{H}(x)$, where $H>0$ is a given constant and $x \geq 0$ is a choice variable representing the quality of the platform. Analogously, the quality of $L$-product is given by $Q_{L}=L+x \equiv Q_{L}(x)$, where $H>L>0$. The monopolist can produce $k$-product $(k=H, L)$ at constant marginal cost $c_{k}+\phi(x)$, where $\phi($.$) is a convex cost function with standard properties, and c_{H}$ and $c_{L}$ are given constants satisfying $c_{H}>c_{L}>0$. In addition, the monopolist incurs fixed

\footnotetext{
${ }^{7}$ See, for example, Waldman (1996) for an analysis focusing on the two-type case.
} 
costs for developing platforms. If the monopolist develops just one type of platform with quality level $x$, the fixed cost is $\eta(x)$. Alternatively, if it develops two types of platforms with quality levels $x_{H}$ for $H$-product and $x_{L}$ for $L$-product $\left(x_{H} \neq x_{L}\right)$, then the fixed cost is $\eta\left(x_{H}\right)+\eta\left(x_{L}\right)$, where $\eta($.$) is a convex cost function with standard properties. In order$ to simplify the analysis and obtain closed form solutions, specify $\phi(x) \equiv \frac{x^{2}}{2}$ and $\eta(x) \equiv \frac{\theta x^{2}}{2}$ where $\theta>0$.

Let the two groups of consumers be denoted groups 1 and 2, where group $j$ consists of a continuum of nonatomic consumers of mass $m_{j}, j=1,2$. A representative individual in group $j$ consumes either zero units or one unit of the products, and derives a gross benefit of $v_{j} Q_{k}(x), k=H$ or $L$ from the consumption of one unit of quality $Q_{k}(x)$ product, where $v_{1}>v_{2}>\frac{c_{L}}{L} \cdot 8$

We consider the two-stage game described below.

[Stage 1] The monopolist determines whether it develops one type of platform with quality $x$, or two types of platforms with quality levels $x_{H}$ for $H$-product and $x_{L}$ for $L$-product, $x_{H} \neq x_{L}$.

[Stage 2] If the monopolist sells both $H$-product and $L$-product, then it chooses their prices, denoted $P_{H}$ and $P_{L}$ respectively. If the monopolist sells $k$-product only, then it chooses its price $P_{k}$. Consumers then make purchase decisions.

In what follows, we say that the monopolist shares a platform between $H$-product and $L$-product if it produces both $H$-product and $L$-product by using one type of platform with quality $x$, while we say that the monopolist does not share a platform if it produces both $H$-product and $L$-product by using two types of platforms with qualities $x_{H}$ and $x_{L}$ respectively.

\subsubsection{Analysis of the monopoly case}

Suppose that the monopolist develops two types of platforms with qualities $x_{H}$ and $x_{L}$, and sells both $H$-product and $L$-product; that is, the monopolist does not share a platform. Under this option, it can be easily shown that the monopolist sells $H$-product with quality $Q_{H}\left(x_{H}\right)$ to all type 1 consumers and $L$-product with quality $Q_{L}\left(x_{L}\right)$ to all type 2 consumers, where $x_{H}>x_{L}>0$ holds. At stage 2 , the monopolist charges the price $P_{L} \equiv v_{2} Q_{L}\left(x_{L}\right)$ to type 2 consumers and the price $P_{H} \equiv v_{1} Q_{H}\left(x_{H}\right)-\left(v_{1}-v_{2}\right) Q_{L}\left(x_{L}\right)$ to type 1 consumers.

\footnotetext{
${ }^{8} v_{2}>\frac{c_{L}}{L}$ implies that the net value of $L$-product is positive even for lower-valuation consumers.
} 
Note that the monopolist can capture the entire surplus from type 2 consumers, while, due to imperfect substitutability between $H$-product and $L$-product, the monopolist has to leave $\left(v_{1}-v_{2}\right) Q_{L}\left(x_{L}\right)$ as a surplus for type 1 consumers. Hence the monopolist's overall profit under this option is given by $\pi_{N P}\left(x_{H}, x_{L}\right)$ ("NP" stands for non-platform-sharing), where

$$
\begin{aligned}
\pi_{N P}\left(x_{H}, x_{L}\right) \equiv & m_{1}\left[v_{1} Q_{H}\left(x_{H}\right)-\left(v_{1}-v_{2}\right) Q_{L}\left(x_{L}\right)-c_{H}-\phi\left(x_{H}\right)\right] \\
& +m_{2}\left[v_{2} Q_{L}\left(x_{L}\right)-c_{L}-\phi\left(x_{L}\right)\right]-\eta\left(x_{H}\right)-\eta\left(x_{L}\right) .
\end{aligned}
$$

Alternatively, suppose that the monopolist develops one type of platform with quality $x$. Then, there are three relevant options for the monopolist. First, the monopolist can share a platform between $H$-product and $L$-product, sell $H$-product with quality $Q_{H}(x)$ at the price of $v_{1} Q_{H}(x)-\left(v_{1}-v_{2}\right) Q_{L}(x)$ to all type 1 consumers, and sell $L$-product with quality $Q_{L}(x)$ at the price of $v_{2} Q_{L}(x)$ to all type 2 consumers. The monopolist's overall profit under this option is given by $\pi_{P S}(x)$ ("PS" stands for platform sharing), where

$$
\pi_{P S}(x) \equiv m_{1}\left[v_{1} Q_{H}(x)-\left(v_{1}-v_{2}\right) Q_{L}(x)-c_{H}-\phi(x)\right]+m_{2}\left[v_{2} Q_{L}(x)-c_{L}-\phi(x)\right]-\eta(x) .
$$

The second option for the monopolist is that it can sell just $H$-product to type 1 and type 2 consumers or to type 1 consumers only. Finally, the third relevant option for the monopolist is to sell just $L$-product to type 1 and type 2 consumers or to type 1 consumers only.

In what follows, we will proceed with our analysis under several parameter restrictions in order to focus our analysis. First, we assume that $v_{2} H-c_{H}>v_{2} L-c_{L} \Leftrightarrow v_{2}>\frac{c_{H}-c_{L}}{H-L}$ holds. Under this assumption, $H$-product is more profitable than $L$-product for the monopolist in the sense that, if it chooses to sell one type of the product, it chooses to sell $H$-product. Second, given that our focus is on the monopolist's decision concerning whether or not to share a platform between $H$-product and $L$-product, we consider a range of parameterizations in which, even if the monopolist develops just one type of platform, it sells both $H$-product and $L$-product. In particular, given Lemma 1 below, we assume (i) $\frac{c_{H}-c_{L}}{H-L}>\frac{\left(m_{1}+m_{2}\right) v_{2}-m_{1} v_{1}}{m_{2}}$, (ii) $\left(m_{1}+m_{2}\right) v_{2}-m_{1} v_{1}>0$, and (iii) $L>\tilde{L}$. Condition (i) implies that the monopolist is better off by selling type- 2 consumers $L$-product rather than $H$-product, and condition (ii) and (iii) together imply that the monopolist is better off by selling type-2 consumers $L$-product rather than nothing.

Lemma 1: Suppose that the monopolist develops one type of platform only. For any given parameterization satisfying $v_{2}>\frac{c_{H}-c_{L}}{H-L}$, there exists a unique value $\tilde{L} \geq 0$ such that 
the monopolist sells both $H$-product and $L$-product in the equilibrium if and only if (i) $\frac{c_{H}-c_{L}}{H-L}>\frac{\left(m_{1}+m_{2}\right) v_{2}-m_{1} v_{1}}{m_{2}}$, (ii) $\left(m_{1}+m_{2}\right) v_{2}-m_{1} v_{1}>0$, and (iii) $L>\tilde{L}$. There exists a range of parameterizations in which (i)-(iii) are satisfied.

We are now ready to present our results.

Proposition 6: There exists a unique value $\tilde{v}_{2}, \frac{m_{1}}{m_{1}+m_{2}} v_{1}<\tilde{v}_{2}<v_{1}$, such that:

(i) If $v_{2}>\tilde{v}_{2}$, the monopolist chooses to share a platform, and sells $H$-product with quality $Q_{H}\left(x^{*}\right)$ to all type 1 consumers and $L$-product with quality $Q_{L}\left(x^{*}\right)$ to all type 2 consumers, where $x^{*}=\frac{m_{1}+m_{2}}{\theta+m_{1}+m_{2}} v_{2}$.

(ii) If $v_{2}<\tilde{v}_{2}$, the monopolist chooses not to share a platform, and sells $H$-product with quality $Q_{H}\left(x_{H}^{*}\right)$ to all type 1 consumers and $L$-product with quality $Q_{L}\left(x_{L}^{*}\right)$ to all type 2 consumers, where $x_{H}^{*}=\frac{m_{1}}{\theta+m_{1}} v_{1}$ and $x_{L}^{*}=\frac{\left(m_{1}+m_{2}\right) v_{2}-m_{1} v_{1}}{\theta+m_{2}}$.

Suppose that the monopolist develops two types of platforms with qualities $x_{H}$ and $x_{L}$ for $H$-product and $L$-product respectively. Given that the platform's quality is an important determinant of the product's quality, the monopolist sets the level of $x_{L}$ lower than the level of $x_{H}$ for two reasons. First, since $L$-product is sold to low-valuation (type 2) consumers and $H$-product is sold to high-valuation (type 1 ) consumers, the marginal benefit of raising the platform's quality is lower for $L$-product. Second, due to imperfect substitutability between $H$-product and $L$-product, the price that the monopolist can charge for $H$-product increases as the quality of $L$-product decreases, and hence it can increase its revenue from $H$-product by reducing $x_{L}$. In other words, by reducing $x_{L}$, the monopolist can reduce the amount of surplus $\left(v_{1}-v_{2}\right) Q_{L}\left(x_{L}\right)$ that has to be left with each type 1 consumer.

Platform sharing reduces the monopolist's profitability by preventing the monopolist from differentiating the quality of the platform for $H$-product and $L$-product. As the value of $v_{2}$ increases, the difference between type 1 consumers and type 2 consumers becomes less important, which in turn reduces the disadvantage of platform sharing for the monopolist. Proposition 1 tells us that when the value of $v_{2}$ exceeds the threshold $\tilde{v}_{2}$, the disadvantage of platform sharing is dominated by its advantage of fixed-cost savings so that the monopolist chooses to share a platform.

Next we turn to welfare consequences of platform sharing.

Proposition 7: Let $C S_{P S}\left(C S_{N P}\right)$ denote the consumer surplus in the equilibrium of the platform-sharing (non-platform-sharing) subgame, and define $T S_{P S}\left(T S_{N P}\right)$ analogously for 
the total surplus. Then

(i) $C S_{P S}>C S_{N P}$ holds for all $v_{2} \in\left(\frac{m_{1}}{m_{1}+m_{2}} v_{1}, v_{1}\right)$.

(ii) There exists a value $\tilde{v}_{2}^{\prime} \in\left[\frac{m_{1}}{m_{1}+m_{2}} v_{1}, \tilde{v}_{2}\right)$ such that $T S_{P S}>T S_{N P}$ holds if $v_{2}>\tilde{v}_{2}^{\prime}$, while $T S_{P S}<T S_{N P}$ holds if $v_{2}<\tilde{v}_{2}^{\prime}$.

As mentioned earlier, in the equilibrium of both subgames the monopolist captures the entire surplus from type 2 consumers, while it has to leave a surplus to be captured by type 1 consumers. If the monopolist does not share a platform, it can reduce the amount of the surplus by reducing the platform's quality for $L$-product. Under platform sharing, however, the monopolist cannot differentiate the quality of platforms for $H$-product and $L$-product, and consequently the surplus for type 1 consumers becomes higher. The result is that the consumer surplus is higher in the platform-sharing subgame than in the non-platformsharing subgame. The monopolist saves on fixed costs by sharing a platform, but the benefit of the fixed-cost saving is in part captured by type 1 consumers. Because of this positive externality to consumers, the total surplus is higher in the platform-sharing subgame than in the non-platform-sharing subgame whenever the monopolist chooses to share a platform.

\subsection{Duopoly case}

\subsubsection{The Model}

We consider the case of duopoly under the structures of supply and demand that are analogous to those in the monopoly case analyzed in the previous subsection. Consider two firms, firm $H$ and firm $L$, that face two groups of consumers. The quality of each firm's product is in part determined by the quality of the platform. In particular, assume that the quality of firm $H$ 's product is given by $Q_{H}=H+x \equiv Q_{H}(x)$ and the quality of firm $L$ 's product is given by $Q_{L}=L+x \equiv Q_{L}(x)$. As in the monopoly case, $x \geq 0$ is a choice variable representing the quality of the platform, and $H>L>0 .{ }^{9}$ Firm $k(=H, L)$ can produce product of quality $Q_{k}(x)$ at constant marginal cost $c_{k}+\phi(x)$ and fixed cost $\eta(x)$, where $\phi(x) \equiv \frac{x^{2}}{2}$ and $\eta(x) \equiv \frac{\theta x^{2}}{2}(\theta>0)$ and $c_{H}>c_{L}>0$. The structure of the demand side is the same as in the monopoly case.

We consider the two-stage game described below.

\footnotetext{
${ }^{9}$ We also assume $H-L>v_{1}$ in the duopoly case, which is a sufficient condition to rule out an equilibrium in which firm $H$ sells $H$-product to type 2 consumers while firm $L$ sells $L$-product to type 1 consumers.
} 
[Stage 1] The two firms jointly determine whether to jointly develop one type of platform or to separately develop their own platforms.

- If they develop platforms separately, each firm $k(=H, L)$ simultaneously and noncooperatively determines the quality of its platform $x_{k}$ by incurring a fixed cost $\frac{\theta x_{k}^{2}}{2}$.

- If they jointly develop one type of platform, firm $H$ and firm $L$ jointly determine the quality of the common platform $x_{C}$ by incurring the joint fixed cost of $\frac{x_{C}^{2}}{2}$. At the same time, they determine a sharing rule $\left(y_{H}, y_{L}\right)$ for the fixed cost, where $y_{H}+y_{L}=\frac{x_{C}^{2}}{2}$ holds. Under the sharing rule, firm $k$ contributes $y_{k}$ towards the joint fixed cost $\frac{x_{C}^{2}}{2} \cdot{ }^{10}$

[Stage 2] Each firm $k$ simultaneously and non-cooperatively announces the price $P_{k}$ of its product, and consumers then make purchase decisions.

In what follows, we say that the two firms share a platform if they jointly develop one type of platform, while we say that they do not share a platform if they develop platforms separately.

\subsubsection{Analysis of the duopoly case}

In what follows we impose the same parameter restrictions as in our analysis of the monopoly case, and focus on cases in which each firm $k(=H, L)$ sells a positive amount of $k$-product in the equilibrium of any stage 2 subgame. In particular, given Lemma 2 below, we assume that $L>\hat{L}$ holds.

Lemma 2: Suppose that firms $H$ and $L$ develop platforms separately at stage 1 . There exists a unique value $\hat{L} \geq 0$ such that in the subsequent stage 2 equilibrium, each firm $k$ sells a positive amount of $k$-product if and only if $L>\hat{L}$.

Suppose that firms $H$ and $L$ jointly develop one type of platform with quality $x_{C}$ at stage 1. Under this option, we find that firms $H$ and $L$ maximize their joint profit by choosing $x_{C}=\frac{m_{1}+m_{2}}{\theta+m_{1}+m_{2}} v_{2} \equiv \hat{x}_{C}^{*}$, which is the same as the monopolist's choice of platform quality under platform sharing. In the subsequent stage 2 equilibrium, firm $H$ sells $H$-product with quality $Q_{H}\left(\hat{x}_{C}^{*}\right)$ at the price of $v_{1} Q_{H}\left(\hat{x}_{C}^{*}\right)-\left(v_{1}-v_{2}\right) Q_{L}\left(\hat{x}_{C}^{*}\right)$ to all type 1 consumers, and firm $L$ sells $L$-product with quality $Q_{L}\left(\hat{x}_{C}^{*}\right)$ at the price of $v_{2} Q_{L}\left(\hat{x}_{C}^{*}\right)$ to all type 2 consumers. Hence

\footnotetext{
${ }^{10}$ We allow the possibility of either $y_{H}$ or $y_{L}$ being negative. In such a case, a side payment is made from one firm to the other.
} 
their joint profit is the same as the monopolist's overall profit when it shares a platform, $\pi_{P S}\left(\hat{x}_{C}^{*}\right)$.

Alternatively, suppose that firms $H$ and $L$ develop platforms separately at stage 1 . Under this option, firm $H$ sells $H$-product with quality $Q_{H}\left(x_{H}\right)$ at the price of $v_{1} Q_{H}\left(x_{H}\right)-\left(v_{1}-\right.$ $\left.v_{2}\right) Q_{L}\left(x_{L}\right)$ to all type 1 consumers, and its overall profit is

$$
\pi_{H}\left(x_{H}, x_{L}\right) \equiv m_{1}\left[v_{1} Q_{H}\left(x_{H}\right)-\left(v_{1}-v_{2}\right) Q_{L}\left(x_{L}\right)-c_{H}-\phi\left(x_{H}\right)\right]-\eta\left(x_{H}\right) .
$$

On the other hand, firm $L$ sells $L$-product with quality $Q_{L}\left(x_{L}\right)$ at the price of $v_{2} Q_{L}\left(x_{L}\right)$ to all type 2 consumers, and its overall profit is

$$
\pi_{L}\left(x_{H}, x_{L}\right) \equiv m_{2}\left(v_{2} Q_{L}\left(x_{L}\right)-c_{L}-\phi\left(x_{L}\right)\right)-\eta\left(x_{L}\right) .
$$

We find that firm $H$ 's optimal choice of platform quality is $\hat{x}_{H}^{*} \equiv \frac{m_{1}}{\theta+m_{1}} v_{1}$, while firm $L$ 's optimal choice is $\hat{x}_{L}^{*} \equiv \frac{m_{2}}{\theta+m_{2}} v_{2}$.

Proposition 8: There exists a unique value $\bar{v}_{2}, \frac{m_{1}}{m_{1}+m_{2}} v_{1} \leq \bar{v}_{2}<v_{1}$, such that (i) and (ii) below hold, where $\frac{m_{1}}{m_{1}+m_{2}} v_{1}<\bar{v}_{2}$ holds if and only if $\theta<\frac{m_{1}^{2}+\sqrt{m_{1}^{4}+4 m_{1} m_{2}^{3}+4 m_{2}^{4}}}{2 m_{2}}$.

(i) If $v_{2}>\bar{v}_{2}$, firms $H$ and $L$ jointly develop one type of platform with quality $\hat{x}_{C}^{*} \equiv$ $\frac{m_{1}+m_{2}}{\theta+m_{1}+m_{2}} v_{2}$, firm $H$ sells $H$-product with quality $Q_{H}\left(\hat{x}_{C}^{*}\right)$ to type 1 consumers, and firm $L$ sells $L$-product with quality $Q_{L}\left(\hat{x}_{C}^{*}\right)$ to type 2 consumers.

(ii) If $v_{2}<\bar{v}_{2}$, firms $H$ and $L$ separately develop platforms with quality $\hat{x}_{H}^{*} \equiv \frac{m_{1}}{\theta+m_{1}} v_{1}$ and $\hat{x}_{L}^{*} \equiv \frac{m_{2}}{\theta+m_{2}} v_{2}$ respectively. Then, firm $H$ sells $H$-product with quality $Q_{H}\left(\hat{x}_{H}^{*}\right)$ to type 1 consumers, and firm $L$ sells $L$-product with quality $Q_{L}\left(\hat{x}_{L}^{*}\right)$ to type 2 consumers.

In addition to the fixed cost savings, there is an additional advantage of platform sharing in the duopoly case. That is, firms $H$ and $L$ can jointly choose the quality of the shared platform at the level that maximizes their joint profit in the subsequent equilibrium. Because of this, firms $H$ and $L$ can achieve a joint profit which is the same amount as the monopolist's profit when it shares a platform. At the same time, however, the quality of platform for $H$ product and $L$-product cannot be differentiated, and this is the disadvantage for the two firms sharing a platform. As in the monopoly case, the disadvantage of platform sharing becomes smaller as the value of $v_{2}$ increases. Proposition 8 tells us that when the value of $v_{2}$ exceeds the threshold $\bar{v}_{2}$, the disadvantage of platform sharing is dominated by its advantage so that the two firms choose to share a platform. 
We now turn to the welfare consequences of platform sharing.

Proposition 9: Let $C S_{P S}\left(C S_{N P}\right)$ denote the consumer surplus in the equilibrium of the platform-sharing (non-platform-sharing) subgame, and define $T S_{P S}\left(T S_{N P}\right)$ analogously for the total surplus. Then

(i) $C S_{P S}>C S_{N P}$ holds for all $v_{2} \in\left(\frac{m_{1}}{m_{1}+m_{2}} v_{1}, v_{1}\right)$.

(ii) There exists a value $\bar{v}_{2}^{\prime} \in\left[\frac{m_{1}}{m_{1}+m_{2}} v_{1}, \bar{v}_{2}\right)$ such that $T S_{P S}>T S_{N P}$ holds if $v_{2}>\bar{v}_{2}^{\prime}$ while $T S_{P S}<T S_{N P}$ holds if $v_{2}<\bar{v}_{2}^{\prime}$.

Platform sharing by firm $H$ and firm $L$ could be perceived as an anticompetitive action because the two firms jointly choose the quality of a shared platform to maximize their joint profit. However, Proposition 9 tells us that platform sharing increases both the consumer surplus and the total surplus whenever the two firms choose to share a platform. The logic here is as follows: Whether or not the two firms share a platform, firm $L$ captures the entire surplus from type 2 consumers by selling them $L$-product at the price of $v_{2} Q_{L}$. On the other hand, due to imperfect substitutability between $H$-product and $L$-product, firm $H$ has to leave $\left(v_{1}-v_{2}\right) Q_{L}$ as a surplus for type 1 consumers. Given that the quality of the platform cannot be differentiated for $H$-product and $L$-product when the two firms share a platform, platform sharing increases the quality of $L$-product in the equilibrium, which in turn increases the consumer surplus by leaving more surplus to be captured by type 1 consumers. The result is that the consumer surplus is higher in the platform-sharing subgame than in the non-platform-sharing subgame. As in the monopoly case, the fixed cost savings from sharing a platform are shared between the firms and the consumers. Consequently, the total surplus is higher in the platform-sharing subgame than in the non-platform-sharing subgame whenever the two firms choose to share a platform.

\subsection{Comparison}

In this subsection we compare the monopoly case and the duopoly case, and explore the welfare consequences of mergers in our framework.

Proposition 10: Platforms are more likely to be shared in the duopoly case than in the monopoly case. More precisely, $\bar{v}_{2}<\tilde{v}_{2}$ holds.

The logic here is as follows: Recall that because of imperfect substitutability between 
$H$-product and $L$-product, the maximum price that can be charged for $H$-product declines as the quality of $L$-product increases. Under non-platform sharing in the monopoly case, the monopolist takes this effect into account when it chooses $x_{L}$ (the quality of the platform for $L$-product). On the other hand, under non-platform sharing in the duopoly case, firm $L$ does not take this effect into account when it chooses $x_{L}$. The result is that under non-platform sharing, the two firms' joint profit in the duopoly case is lower than the monopolist's profit in the monopoly case, which in turn implies that the producers' benefit of platform sharing is higher in the duopoly case. This results in $\bar{v}_{2}<\tilde{v}_{2}$.

Finally, in Proposition 11 we consider welfare consequences of the merger between firm $H$ and $L$.

\section{Proposition 11:}

(i) If $v_{2}<\tilde{v}_{2}$, then the merger between firm $H$ and firm $L$ increases the producer surplus while it reduces the consumer surplus and the total surplus.

(ii) If $v_{2}>\tilde{v}_{2}$, then the merger between firm $H$ and firm $L$ does not affect the producer surplus, the consumer surplus, or the total surplus.

If $v_{2}<\bar{v}_{2}\left(<\tilde{v}_{2}\right.$ by Proposition 10), a platform is not shared in the monopoly case or the duopoly case. The monopolist maximizes its profit by lowering the platform's quality for $L$-product at an optimally low level, while the quality of the platform for $L$-product is chosen to be higher in the duopoly case. The higher platform quality of $L$-product results in a higher consumer surplus and total surplus and a lower producer surplus in the duopoly case. Suppose $v_{2}$ takes a higher value so that $\bar{v}_{2}<v_{2}<\tilde{v}_{2}$ holds. Then a platform is shared in the duopoly case and not shared in the monopoly case. Platform sharing further increases the platform quality of $L$-product, which results in a higher consumer surplus and total surplus in the duopoly case. Finally, if $v_{2}>\tilde{v}_{2}$, a platform is shared in both cases. In the duopoly case, firm $H$ and firm $L$ jointly choose the quality of the platform that maximizes their joint profit in the subsequent equilibrium, and so the equilibrium outcomes are the same across the monopoly case and the duopoly case.

In our framework, the merger can reduce the consumer surplus through two channels when $v_{2}<\tilde{v}_{2}$ (so that the monopolist does not share a platform). The merged firm maximizes its profitability by setting the platform quality of $L$-product lower, which reduces the surplus captured by type 1 consumers. Furthermore, the merger makes platform sharing less attractive for producers, and this can further reduce the consumer surplus because platform 
sharing benefits type 1 consumers by increasing the surplus they can capture.

\section{Conclusion}

We have explored the managerial implications and economic consequences of platform sharing by analyzing two models; one model incorporates platform sharing into a horizontal product differentiation model, and the other incorporates it into a vertical product differentiation model. In this section we conclude the paper by discussing relationships between platform sharing under horizontal product differentiation and that under vertical product differentiation.

In both models, the advantage of platform sharing is, simply, fixed-cost savings. That is, firms can save on fixed costs for platform development by using a common platform across two different products. In the horizontal product differentiation model, platform sharing reduces firms' profitability by decreasing the representative consumer's willingness to pay. Also, in the duopoly case, platform sharing further reduces firms' profitability by intensifying competition between firms. In the vertical product differentiation model, the quality of platform for the high-quality product and that for the low-quality product cannot be differentiated under platform sharing, and this is the disadvantage of platform sharing for producers. The disadvantage is relatively small when the loss of product differentiation due to platform sharing is small (in the former model) or when the difference between high-valuation consumers and low-valuation consumers is small (in the latter model), and a common platform is shared in the equilibrium when the disadvantage is small enough.

It might appear that platform sharing across firms makes consumers worse off because firms cooperate in their product development process by sharing a common platform to maximize their joint profit. We have found, however, that in our duopoly cases, platform sharing increases consumer surplus in both models. In the horizontal product differentiation model, platform sharing reduces product variety which consumers prefer. At the same time, platform sharing also intensifies competition between the two firms, and we have found that this positive effect on consumers dominates the negative effect of reduced product variety so that platform sharing increases consumer surplus. In the vertical product differentiation model, the equilibrium quality of the low-quality product is higher under platform sharing, and this in turn increases the amount of surplus that high-valuation consumers can capture.

In the monopoly case, platform sharing under vertical product differentiation makes 
consumers better off through the same logic as in the duopoly case mentioned above. On the other hand, platform sharing under horizontal product differentiation makes consumers worse off, because platform sharing cannot benefit consumers by intensifying competition in the monopoly case. In other words, welfare consequences of platform sharing under horizontal product differentiation critically depends on the competitiveness of the product market. This finding suggests that antitrust authorities should carefully investigate the competitiveness of product market in order to determine welfare consequences of platform sharing if it is under horizontal product differentiation.

By incorporating platform sharing into product differentiation models, our analyses have shown new channels through which mergers negatively affect consumers. In the horizontal differentiation model, a merger can induce the merged firm to share a platform, which further decreases the consumer surplus by reducing product variety. In the vertical differentiation model, a platform is less likely to be shared when the two firms merge to become one firm. This negatively affects consumers because more surplus can be captured by consumers under platform sharing in this model.

In this paper we have analyzed platform sharing under horizontal product differentiation and that under vertical product differentiation separately in two different models. In reality, a common platform is often shared across products that are differentiated both horizontally and vertically. In our future work, we plan to analyze platform sharing in such a setup. 


\section{Appendix}

Proof of Proposition 1: Inequality (3) is equivalent to $s-h(x) \geq 0$, where $h(x) \equiv$ $\frac{a^{2} x}{4 F\left(1+b_{0}\right)\left(1+b_{0}+x\right)}$. We have (i) $s-h(0)=s>0$, (ii) $\lim _{x \rightarrow 1-b_{0}} s-h(x)=s-\frac{a^{2}\left(1-b_{0}\right)}{8 F\left(1+b_{0}\right)}<0$ and (iii) $h^{\prime}(x)=\frac{a^{2}}{4 F\left(1+b_{0}+x\right)^{2}}>0$. Together (i) - (iii) imply that there exists a unique value $\breve{x} \in\left(0,1-b_{0}\right)$ such that $s-h(x)>(=,<) 0$ if and only if $x<(=,>) \breve{x}$, where $s-h(\breve{x}) \equiv 0$. We have that $\frac{d \breve{x}}{d s}=\frac{1}{h^{\prime}(\breve{x})}>0$, and letting $\breve{x} \equiv x^{m}(s)$ implies the result. Q.E.D.

Proof of Proposition 2: Define $C S^{m}(b) \equiv U\left(q_{1}^{m}(b), q_{2}^{m}(b)\right)-p_{1}^{m}(b) q_{1}^{m}(b)-p_{2}^{m}(b) q_{2}^{m}(b)=$ $\frac{a^{2}}{4(1+b)}$. We then find $C S_{P S}-C S_{N P}=C S^{m}\left(b_{0}+x\right)-C S^{m}\left(b_{0}\right)=-\frac{a^{2} x}{4\left(1+b_{0}\right)\left(1+b_{0}+x\right)}<0$ for all $x \in\left(0,1-b_{0}\right)$. This proves $2(\mathrm{i})$. Regarding $2(\mathrm{ii})$, we have $\pi_{P S}-\pi_{N P}=2 s F-\frac{2 a^{2} x}{4\left(1+b_{0}\right)\left(1+b_{0}+x\right)}=$ $2 F(s-h(x))$, and hence $T S_{P S}-T S_{N P}=\pi_{P S}-\pi_{N P}+C S_{P S}-C S_{N P}=2 F(s-h(x))-$ $\frac{a^{2} x}{4\left(1+b_{0}\right)\left(1+b_{0}+x\right)} \equiv g(x)$. We have $g(0)=2 s F>0, g\left(x^{m}(s)\right)=-\frac{a^{2} x^{m}(s)}{4\left(1+b_{0}\right)\left(1+b_{0}+x^{m}(s)\right)}<0$ and $g^{\prime}(x)=-2 F h^{\prime}(x)-\frac{a^{2}}{4\left(\left(1+b_{0}+x\right)^{2}\right.}<0$. This implies 2(ii). Q.E.D.

Proof of Proposition 3: Firms 1 and 2 share platform in stage 1 if and only if $s F \geq \pi^{d}\left(b_{0}\right)-$ $\pi^{d}\left(b_{0}+x\right)$ which is equivalent to $s-k(x) \geq 0$, where $k(x) \equiv \frac{a^{2}\left(1-b_{0}\right)}{F\left(2-b_{0}\right)^{2}\left(1+b_{0}\right)}-\frac{a^{2}\left(1-b_{0}-x\right)}{F\left(2-b_{0}-x\right)^{2}\left(1+b_{0}+x\right)}$. We have (i) $s-k(0)=s>0$, (ii) $\lim _{x \rightarrow 1-b_{0}} s-k(x)=s-\frac{a^{2}\left(1-b_{0}\right)}{F\left(2-b_{0}\right)^{2}\left(1+b_{0}\right)}<0$, and (iii) $k^{\prime}(x)=\frac{2 a^{2}\left(1-\left(b_{0}+x\right)+\left(b_{0}+x\right)^{2}\right)}{F\left(2-\left(b_{0}+x\right)\right)^{3}\left(1+\left(b_{0}+x\right)\right)^{2}}>0$. Together (i) - (iii) imply that there exists a unique value $\breve{x} \in\left(0,1-b_{0}\right)$ such that $s-k(x)>(=,<) 0$ if and only if $x<(=,>) \breve{x}$, where $s-k(\breve{x}) \equiv 0$. We have that $\frac{d \breve{x}}{d s}=\frac{1}{k^{\prime}(\breve{x})}>0$, and letting $\breve{x} \equiv x^{d}(s)$ implies the result. Q.E.D.

Proof of Proposition 4: Define $C S^{d}(b) \equiv U\left(q_{1}^{d}(b), q_{2}^{d}(b)\right)-p_{1}^{d}(b) q_{1}^{d}(b)-p_{2}^{d}(b) q_{2}^{d}(b)=$ $\frac{a^{2}(1-b)}{(2-b)^{2}(1+b)}$. Then, given $C S_{N P}=C S^{d}\left(b_{0}\right)$ and $C S_{P S}=C S^{d}\left(b_{0}+x\right), \frac{d C S^{d}(b)}{d b}=\frac{3 a^{2} b}{(2-b)^{3}(1+b)^{2}}>0$ implies 4(i). We have that $T S_{P S} \equiv C S_{P S}+2 \pi_{P S}$ and $T S_{N P} \equiv C S_{N P}+2 \pi_{N P}$, and that $C S_{P S}>C S_{N P}$ and $\pi_{P S} \geq \pi_{N P}$ for all $x \in\left(0, x^{d}(s)\right]$. Then $\frac{d\left(T S_{P S}-T S_{N P}\right)}{d x}=-\frac{4-7(b+x)+4(b+x)^{2}}{(2-b-x)^{3}(1+b+x)}<$ 0 implies 4(ii). Q.E.D.

Proof of Proposition 5: Recall that platform is shared in the monopoly case if $2 s F \geq$ $\pi^{m}\left(b_{0}\right)-\pi^{m}\left(b_{0}+x\right)$ while it is shared in duopoly if $s F \geq \pi^{d}\left(b_{0}\right)-\pi^{d}\left(b_{0}+x\right)$. Proofs of Propositions 1 and 3 then imply that, to prove Proposition 5, it suffices to show that $\pi^{m}\left(b_{0}\right)-\pi^{m}\left(b_{0}+x^{d}(s)\right)<2 \pi^{d}\left(b_{0}\right)-2 \pi^{d}\left(b_{0}+x^{d}(s)\right)=2 s F$. Define $L(b) \equiv \pi^{m}(b)-2 \pi^{d}(b)$, and we find $L^{\prime}(b)=\frac{b^{2}}{2(1+b)(2-b)^{2}}>0$. This implies $L\left(b_{0}+x\right)>L\left(b_{0}\right) \Leftrightarrow \pi^{m}\left(b_{0}\right)-\pi^{m}\left(b_{0}+x\right)<$ $2 \pi^{d}\left(b_{0}\right)-2 \pi^{d}\left(b_{0}+x\right)$ holds for all $x \in\left(0,1-b_{0}\right)$. This implies the result. Q.E.D. 
Proof of Lemma 1: Suppose that the monopolist develops just one type of platform with quality $x$. We first establish the following claim.

Claim 1: There does not exist an equilibrium in which the monopolist sells $H$-product to type 2 consumers and $L$-product to type 1 consumers.

Proof: Suppose such an equilibrium exists, and let $P_{H}\left(P_{L}\right)$ denote the price of $H$-product ( $L$-product) in the equilibrium. Then $P_{H} \leq v_{2} Q_{H}$ and $v_{1} Q_{L}-P_{L} \geq v_{1} Q_{H}-P_{H}$ must hold, where $Q_{H} \equiv Q_{H}(x)$ and $Q_{L} \equiv Q_{L}(x)$. We then have that $v_{2} Q_{L}-P_{L} \geq v_{2} Q_{L}-v_{1} Q_{L}+v_{1} Q_{H}-$ $P_{H}>v_{2} Q_{H}-P_{H}$, where the second inequality is implied by $\left(v_{1}-v_{2}\right)\left(Q_{H}-Q_{L}\right)>0$. But $v_{2} Q_{L}-P_{L}>v_{2} Q_{H}-P_{H}$ implies that type 2 consumers purchase $L$-product. A contradiction. Q.E.D.

Claim 1 implies that, if the monopolist sells both $H$-product and $L$-product, it sells $H$ product to all type 1 consumers and $L$-product to all type 2 consumers, and the monopolist's overall profit under this option is $\pi_{P S}(x)$ as defined in the text. Substituting and rearranging yield

$$
\pi_{P S}(x)=\left(m_{1}+m_{2}\right) v_{2} x-\frac{\theta+m_{1}+m_{2}}{2} x^{2}+Z_{1},
$$

where $Z_{1} \equiv m_{1} v_{1} H+\left[\left(m_{1}+m_{2}\right) v_{2}-m_{1} v_{1}\right] L-m_{1} c_{H}-m_{2} c_{L}$. Hence, under this option the monopolist chooses $x=\frac{m_{1}+m_{2}}{\theta+m_{1}+m_{2}} v_{2} \equiv x^{*}$, and its maximized profit is

$$
\pi_{P S}\left(x^{*}\right)=\frac{\left[\left(m_{1}+m_{2}\right) v_{2}\right]^{2}}{2\left(\theta+m_{1}+m_{2}\right)}+Z_{1}
$$

Given $v_{2}>\frac{c_{H}-c_{L}}{H-L}$, the relevant alternative option for the monopolist is to sell $H$-product only. The monopolist can sell $H$-product to type 1 consumers at the price of $v_{1} Q_{H}(x)$, and its overall profit in this case is

$$
\pi_{H 1}(x) \equiv m_{1} v_{1} x-\frac{\theta+m_{1}}{2} x^{2}+Z_{2},
$$

where $Z_{2} \equiv m_{1} v_{1} H-m_{1} c_{H}$. The monopolist chooses $x=\frac{m_{1}}{\theta+m_{1}} v_{1} \equiv x_{H 1}^{*}$ in this case, and its maximized profit is

$$
\pi_{H 1}^{*} \equiv \frac{\left(m_{1} v_{1}\right)^{2}}{2\left(\theta+m_{1}\right)}+Z_{2}
$$

Alternatively, the monopolist can sell $H$-product to both type 1 and type 2 consumers at the price of $v_{2} Q_{H}(x)$, and we find that its maximized overall profit in this case is

$$
\pi_{H 12}^{*} \equiv \frac{\left[\left(m_{1}+m_{2}\right) v_{2}\right]^{2}}{2\left(\theta+m_{1}+m_{2}\right)}+Z_{3}
$$


where $Z_{3} \equiv\left(m_{1}+m_{2}\right) v_{2} H-\left(m_{1}+m_{2}\right) c_{H}$.

We have that $\pi_{P S}\left(x^{*}\right)>\pi_{H 12}^{*} \Leftrightarrow \frac{c_{H}-c_{L}}{H-L}>\frac{\left(m_{1}+m_{2}\right) v_{2}-m_{1} v_{1}}{m_{2}}$. Also, comparison of $\pi_{P S}\left(x^{*}\right)$ and $\pi_{H 1}^{*}$ yields that $\left(m_{1}+m_{2}\right) v_{2}-m_{1} v_{1}>0$ must hold for $\pi_{P S}\left(x^{*}\right)>\pi_{H 1}^{*}$ to hold, and that, given $\left(m_{1}+m_{2}\right) v_{2}-m_{1} v_{1}>0$, there exists a unique value $\tilde{L}\left(\theta, m_{1}, m_{2}, v_{1}, v_{2}, c_{L}\right)$ such that $\pi_{P S}\left(x^{*}\right)>\pi_{H 1}^{*} \Leftrightarrow L>\tilde{L}\left(\theta, m_{1}, m_{2}, v_{1}, v_{2}, c_{L}\right)$. Then, Claim 2 below completes the proof of Lemma 1.

Claim 2: There exists a range of parameterizations in which $\left(m_{1}+m_{2}\right) v_{2}-m_{1} v_{1}>0$, $v_{2}>\frac{c_{H}-c_{L}}{H-L}>\frac{\left(m_{1}+m_{2}\right) v_{2}-m_{1} v_{1}}{m_{2}}$, and $L>\tilde{L}\left(\theta, m_{1}, m_{2}, v_{1}, v_{2}, c_{L}\right)$ hold.

Proof: First note that $v_{1}>v_{2} \Rightarrow v_{2}>\frac{\left(m_{1}+m_{2}\right) v_{2}-m_{1} v_{1}}{m_{2}}$. Pick any $\theta, m_{1}, m_{2}, v_{1}, v_{2}, c_{L}$, and $L$ that satisfy $\left(m_{1}+m_{2}\right) v_{2}-m_{1} v_{1}>0$ and $L>\tilde{L}\left(\theta, m_{1}, m_{2}, v_{1}, v_{2}, c_{L}\right)$. We can pick $H$ and $c_{H}$ such that $v_{2}>\frac{c_{H}-c_{L}}{H-L}>\frac{\left(m_{1}+m_{2}\right) v_{2}-m_{1} v_{1}}{m_{2}}$ holds. Q.E.D.

Proof of Proposition 6: Suppose that the monopolist sells $H$-product with platform quality $x_{H}$ and $L$-product with platform quality $x_{L}$ in the equilibrium, where $x_{H} \neq x_{L}$. Through the procedure analogous to the proof of Claim 1, we find that the monopolist sells $H$-product to all type 1 consumers and $L$-product to all type 2 consumers in the equilibrium, and the monopolist's overall profit under this option is $\pi_{N P}\left(x_{H}, x_{L}\right)$ as defined in the text. Substituting and rearranging yield

$$
\pi_{N P}\left(x_{H}, x_{L}\right)=m_{1} v_{1} x_{H}-\frac{\theta+m_{1}}{2} x_{H}^{2}+\left[\left(m_{1}+m_{2}\right) v_{2}-m_{1} v_{1}\right] x_{L}-\frac{\theta+m_{2}}{2} x_{L}^{2}+Z_{1},
$$

where $Z_{1}=m_{1} v_{1} H+\left[\left(m_{1}+m_{2}\right) v_{2}-m_{1} v_{1}\right] L-m_{1} c_{H}-m_{2} c_{L}$. Hence, under this option the monopolist chooses $x_{H}=\frac{m_{1}}{\theta+m_{1}} v_{1} \equiv x_{H}^{*}$ and $x_{L}=\frac{\left(m_{1}+m_{2}\right) v_{2}-m_{1} v_{1}}{\theta+m_{2}} \equiv x_{L}^{*}$, and its maximized profit is

$$
\pi_{N P}\left(x_{H}^{*}, x_{L}^{*}\right)=\frac{\left(m_{1} v_{1}\right)^{2}}{2\left(\theta+m_{1}\right)}+\frac{\left[\left(m_{1}+m_{2}\right) v_{2}-m_{1} v_{1}\right]^{2}}{2\left(\theta+m_{2}\right)}+Z_{1}
$$

Given Lemma 1, Claim 3 below completes the proof of Proposition 6.

Claim 3: There exists a unique value $\tilde{v}_{2}, \frac{m_{1}}{m_{1}+m_{2}} v_{1}<\tilde{v}_{2}<v_{1}$, such that $\pi_{P S}\left(x^{*}\right)>$ $\pi_{N P}\left(x_{H}^{*}, x_{L}^{*}\right)$ if $v_{2}>\tilde{v}_{2}$ while $\pi_{P S}\left(x^{*}\right)<\pi_{N P}\left(x_{H}^{*}, x_{L}^{*}\right)$ if $v_{2}<\tilde{v}_{2}$.

Proof: We have that $\pi_{P S}\left(x^{*}\right)>\pi_{N P}\left(x_{H}^{*}, x_{L}^{*}\right)$ if $v_{2}=v_{1}$, and $\pi_{P S}\left(x^{*}\right)<\pi_{N P}\left(x_{H}^{*}, x_{L}^{*}\right)$ if $v_{2}=\frac{m_{1}}{m_{1}+m_{2}} v_{1}$. We also have that $\frac{\partial}{\partial v_{2}} \pi_{P S}\left(x^{*}\right)>\frac{\partial}{\partial v_{2}} \pi_{N P}\left(x_{H}^{*}, x_{L}^{*}\right) \Leftrightarrow v_{1}>\frac{m_{1}+m_{2}}{\theta+m_{1}+m_{2}} v_{2}$, and this condition is satisfied because $v_{1}>v_{2}$ and $\theta>0$. Then the Intermediate Value Theorem implies the result. Q.E.D. 
Proof of Proposition 7: First note that each type 2 consumer's surplus is zero in the equilibrium of both subgames. Each type 1 consumer's surplus is $\left(v_{1}-v_{2}\right) Q_{L}\left(x^{*}\right)\left(\left(v_{1}-\right.\right.$ $\left.v_{2}\right) Q_{L}\left(x_{L}^{*}\right)$ ) in the equilibrium of platform sharing (non-platform sharing) subgame, where $x^{*}=\frac{m_{1}+m_{2}}{\theta+m_{1}+m_{2}} v_{2}>x_{L}^{*}=\frac{\left(m_{1}+m_{2}\right) v_{2}-m_{1} v_{1}}{\theta+m_{2}} v_{2}$ implies $\left(v_{1}-v_{2}\right) Q_{L}\left(x^{*}\right)>\left(v_{1}-v_{2}\right) Q_{L}\left(x_{L}^{*}\right)$. This implies (i). Regarding the total surplus, given $T S_{P S}=\pi_{P S}\left(x^{*}\right)+m_{1}\left(v_{1}-v_{2}\right) Q_{L}\left(x^{*}\right) \equiv$ $T S_{P S}\left(x^{*}\right)$ and $T S_{N P}=\pi_{N P}\left(x_{H}^{*}, x_{L}^{*}\right)+m_{1}\left(v_{1}-v_{2}\right) Q_{L}\left(x_{L}^{*}\right) \equiv T S_{N P}\left(x_{H}^{*}, x_{L}^{*}\right)$, we find that $\frac{\partial}{\partial v_{2}}\left(T S_{P S}-T S_{N P}\right)=\frac{m_{1}\left[\theta m_{2} v_{1}-\left(v_{1}-v_{2}\right)\left(m_{1}^{2}-m_{2}^{2}\right)\right]}{\left(\theta+m_{1}+m_{2}\right)\left(\theta+m_{2}\right)}$, which takes the same sign for all $v_{2} \in\left(\frac{m_{1}}{m_{1}+m_{2}} v_{1}, v_{1}\right)$. Proposition 6 and $7(\mathrm{i})$ then imply $7($ ii). Q.E.D.

Proof of Lemma 2: Suppose that firms $H$ and $L$ develop platforms separately at stage 1, and each firm $k(=H, L)$ sells a positive amount of $k$-product in the subsequent equilibrium. Through a procedure analogous to the proof of Claim 1, we find that there does not exist a subsequent equilibrium in which firm $H$ sells $H$-product to type 2 consumers and firm $L$ sells $L$-product to type 1 consumers. Then, firm $k$ 's overall profit in the equilibrium is $\pi_{k}\left(x_{H}, x_{L}\right)$, which is as defined in the text. Substituting and rearranging yield

$$
\pi_{H}\left(x_{H}, x_{L}\right)=m_{1} v_{1} x_{H}-\frac{\theta+m_{1}}{2} x_{H}^{2}-m_{1}\left(v_{1}-v_{2}\right) x_{L}+Z_{4},
$$

where $Z_{4} \equiv m_{1}\left[v_{1}(H-L)+v_{2} L-c_{H}\right]$, and

$$
\pi_{L}\left(x_{H}, x_{L}\right)=m_{2} v_{2} x_{L}-\frac{\theta+m_{2}}{2} x_{L}^{2}+Z_{5},
$$

where $Z_{5} \equiv m_{2}\left(v_{2} L-c_{L}\right)$. We then find that the optimal choices of platform quality of firms $H$ and $L$ are $x_{H}^{*} \equiv \frac{m_{1}}{\theta+m_{1}} v_{1}$ and $x_{L}^{*} \equiv \frac{m_{2}}{\theta+m_{2}} v_{2}$ respectively, and

$$
\begin{gathered}
\pi_{H}\left(x_{H}^{*}, x_{L}^{*}\right)=\frac{\left(m_{1} v_{1}\right)^{2}}{2\left(\theta+m_{1}\right)}-\frac{m_{1} m_{2}\left(v_{1}-v_{2}\right) v_{2}}{\theta+m_{2}}+Z_{4}, \\
\pi_{L}\left(x_{H}^{*}, x_{L}^{*}\right)=\frac{\left(m_{2} v_{2}\right)^{2}}{2\left(\theta+m_{2}\right)}+Z_{5} .
\end{gathered}
$$

Now suppose that, given $x_{L}=x_{L}^{*}$, firm $H$ chooses $x_{H}$ and sells $H$-product to all type 1 and type 2 consumers at stage 2 . Then $v_{2}\left(H+x_{H}\right)-P_{H}=v_{2}\left(L+x_{L}^{*}\right)-P_{L}$ holds, where $P_{k}$ denotes the price firm $k$ chooses. In the equilibrium $P_{L}=c_{L}+\frac{\left(x_{L}^{*}\right)^{2}}{2}$ holds, and hence $P_{H}=v_{2}\left(H+x_{H}\right)-v_{2}\left(L+x_{L}^{*}\right)+c_{L}+\frac{\left(x_{L}^{*}\right)^{2}}{2}$. Firm H's overall profit under this option is then

$$
\begin{aligned}
\tilde{\pi}_{H}\left(x_{H}, x_{L}^{*}\right) & =\left(m_{1}+m_{2}\right)\left(P_{H}-c_{H}-\frac{x_{H}^{2}}{2}\right)-\frac{\theta x_{H}^{2}}{2} \\
& =\left(m_{1}+m_{2}\right) v_{2} x_{H}-\frac{\theta+m_{1}+m_{2}}{2} x_{H}^{2}-\left(m_{1}+m_{2}\right)\left(v_{2} x_{L}^{*}-\frac{\left(x_{L}^{*}\right)^{2}}{2}\right)+Z_{6}(20)
\end{aligned}
$$


where $Z_{6} \equiv\left(m_{1}+m_{2}\right)\left[v_{2}(H-L)-\left(c_{H}-c_{L}\right)\right]$. We then find that firm $H$ chooses $x_{H}=$ $\frac{m_{1}+m_{2}}{\theta+m_{1}+m_{2}} v_{2} \equiv x_{H}^{* *}$, and

$$
\tilde{\pi}_{H}\left(x_{H}^{* *}, x_{L}^{*}\right)=\frac{\left[\left(m_{1}+m_{2}\right) v_{2}\right]^{2}}{2\left(\theta+m_{1}+m_{2}\right)}-\left(m_{1}+m_{2}\right)\left(v_{2} x_{L}^{*}-\frac{\left(x_{L}^{*}\right)^{2}}{2}\right)+Z_{6} .
$$

Now suppose that, given $x_{H}=x_{H}^{*}$, firm $L$ chooses $x_{L}$ and sells $L$-product to all type 1 and type 2 consumers at Stage 2. Through the analogous procedure we find that firm $L$ chooses $x_{L}=\frac{m_{1}+m_{2}}{\theta+m_{1}+m_{2}} v_{2} \equiv x_{L}^{* *}$, and its overall profit is

$$
\tilde{\pi}_{L}\left(x_{H}^{*}, x_{L}^{* *}\right)=\frac{\left[\left(m_{1}+m_{2}\right) v_{2}\right]^{2}}{2\left(\theta+m_{1}+m_{2}\right)}-\left(m_{1}+m_{2}\right)\left(v_{2} x_{H}^{*}-\frac{\left(x_{H}^{*}\right)^{2}}{2}\right)-Z_{6} .
$$

We then find that in the subsequent stage 2 equilibrium, each firm $k(=H, L)$ sells a positive amount of $k$-product if and only if $\pi_{H}\left(x_{H}^{*}, x_{L}^{*}\right)>\tilde{\pi}_{H}\left(x_{H}^{* *}, x_{L}^{*}\right)$ and $\pi_{L}\left(x_{H}^{*}, x_{L}^{*}\right)>$ $\tilde{\pi}_{L}\left(x_{H}^{*}, x_{L}^{* *}\right)$ hold, where the latter inequality holds for all $L$. Finally, comparison of (18) and (21) yields that there exists a unique value $\hat{L} \geq 0$ such that $\pi_{H}\left(x_{H}^{*}, x_{L}^{*}\right)>\tilde{\pi}_{H}\left(x_{H}^{* *}, x_{L}^{*}\right)$ holds if and only if $L \geq \hat{L}$. Q.E.D.

Proof of Proposition 8: Suppose that firms $H$ and $L$ jointly develop one type of platform with quality $x_{C}$. The analysis of the monopoly case implies that their joint profit is maximized when they choose $x_{C}=\frac{m_{1}+m_{2}}{\theta+m_{1}+m_{2}} v_{2} \equiv \hat{x}_{C}^{*}$, and then firm $H$ sells $H$-product with quality $Q_{H}\left(\hat{x}_{C}^{*}\right)$ to all type 1 consumers while firm $L$ sells $L$-product with quality $Q_{L}\left(\hat{x}_{C}^{*}\right)$ to all type 2 consumers. We establish the following claim.

Claim 4: Suppose that firms $H$ and $L$ jointly developed one type of platform with quality $\hat{x}_{C}^{*}$ at stage 1 . Then, in the subsequent equilibrium, firm $H$ sells $H$-product with quality $Q_{H}\left(\hat{x}_{C}^{*}\right)$ to all type 1 consumers while firm $L$ sells $L$-product with quality $Q_{L}\left(\hat{x}_{C}^{*}\right)$ to all type 2 consumers.

Proof: In the equilibrium described above, firm $H^{\prime}$ 's stage 2 profit is

$\pi_{H}\left(\hat{x}_{C}^{*}\right) \equiv m_{1}\left[v_{1} Q_{H}\left(\hat{x}_{C}^{*}\right)-\left(v_{1}-v_{2}\right) Q_{L}\left(\hat{x}_{C}^{*}\right)-c_{H}-\frac{\left(\hat{x}_{C}^{*}\right)^{2}}{2}\right]=m_{1}\left[v_{1} H-\left(v_{1}-v_{2}\right) L-c_{H}+v_{2} \hat{x}_{C}^{*}-\frac{\left(\hat{x}_{C}^{*}\right)^{2}}{2}\right]$.

Now suppose that firm $H$ sells $H$-product with quality $Q_{H}\left(\hat{x}_{C}^{*}\right)$ to all consumers at the price of $P_{H}$ in the subsequent equilibrium. Then $v_{2} Q_{H}\left(\hat{x}_{C}^{*}\right)-P_{H} \geq v_{2} Q_{L}\left(\hat{x}_{C}^{*}\right)-P_{L} \Leftrightarrow P_{H} \leq$ $v_{2}(H-L)+P_{L}$ must hold, where $P_{L}=c_{L}+\frac{\left(\hat{x}_{C}^{*}\right)^{2}}{2}$. Let $P_{H}=v_{2}(H-L)+c_{L}+\frac{\left(\hat{x}_{C}^{*}\right)^{2}}{2}$. Then firm $H$ 's stage 2 profit is

$$
\tilde{\pi}_{H}\left(\hat{x}_{C}^{*}\right) \equiv\left(m_{1}+m_{2}\right)\left(P_{H}-c_{H}-\frac{\left(\hat{x}_{C}^{*}\right)^{2}}{2}\right)=\left(m_{1}+m_{2}\right)\left[v_{2}(H-L)-\left(c_{H}-c_{L}\right)\right] .
$$


Note that we have $\left(m_{1}+m_{2}\right) v_{2} \hat{x}_{C}^{*}-\left(\theta+m_{1}+m_{2}\right) \frac{\left(\hat{x}_{C}^{*}\right)^{2}}{2}>0 \Rightarrow v_{2} \hat{x}_{C}^{*}-\frac{\left(\hat{x}_{C}^{*}\right)^{2}}{2}>0$, and $v_{2} L-c_{L}>0$. We then have that $\pi_{H}\left(\hat{x}_{C}^{*}\right)>m_{1}\left(v_{1} H-v_{1} L+v_{2} L-c_{L}-c_{H}+c_{L}\right)>$ $m_{1}\left[v_{1}(H-L)-\left(c_{H}-c_{L}\right)\right]>\left(m_{1}+m_{2}\right)\left[v_{2}(H-L)-\left(c_{H}-c_{L}\right)\right]=\tilde{\pi}_{H}\left(\hat{x}_{C}^{*}\right)$, where the last inequality is implied by $\frac{c_{H}-c_{L}}{H-L}>\frac{\left(m_{1}+m_{2}\right) v_{2}-m_{1} v_{1}}{m_{2}}$. Hence, there does not exist an equilibrium in which firm $H$ sells $H$-product with quality $Q_{H}\left(\hat{x}_{C}^{*}\right)$ to all consumers. Similarly, we find that there does not exit an equilibrium in which firm $L$ sells $L$-product with quality $Q_{L}\left(\hat{x}_{C}^{*}\right)$ to all consumers. Finally, through a procedure analogous to the proof of Claim 1, we find that there does not exist an equilibrium in which firm $H$ sells $H$-product to type 2 consumers and firm $L$ sells $L$-product to type 1 consumers. Q.E.D.

Claim 4 implies that, if firms $H$ and $L$ jointly develop one type of platform, they choose $x_{C}=\hat{x}_{C}^{*}$ to maximize their joint profit, where the maximized joint profit is

$$
\pi_{P S}\left(\hat{x}_{C}^{*}\right)=\frac{\left[\left(m_{1}+m_{2}\right) v_{2}\right]^{2}}{2\left(\theta+m_{1}+m_{2}\right)}+Z_{1}
$$

where $Z_{1} \equiv m_{1} v_{1} H+\left[\left(m_{1}+m_{2}\right) v_{2}-m_{1} v_{1}\right] L-m_{1} c_{H}-m_{2} c_{L}$.

From Lemma 2 and its proof we have that, if firms $H$ and $L$ develop platforms separately, their joint profit in the subsequent equilibrium is

$$
\pi_{H}\left(\hat{x}_{H}^{*}, \hat{x}_{L}^{*}\right)+\pi_{L}\left(\hat{x}_{H}^{*}, \hat{x}_{L}^{*}\right)=g_{N P}\left(\theta, m_{1}, m_{2}, v_{1}, v_{2}\right)+Z_{1},
$$

where $g_{N P}\left(\theta, m_{1}, m_{2}, v_{1}, v_{2}\right) \equiv \frac{\left(m_{1} v_{1}\right)^{2}}{2\left(\theta+m_{1}\right)}+\frac{\left(m_{2} v_{2}\right)^{2}}{2\left(\theta+m_{2}\right)}-m_{1}\left(v_{1}-v_{2}\right) \frac{m_{2} v_{2}}{\theta+m_{2}}$. On the other hand, if firms $H$ and $L$ jointly develop one type of platform, their joint profit in the subsequent equilibrium is

$$
\pi_{P S}\left(\hat{x}_{C}^{*}\right)=g_{P S}\left(\theta, m_{1}, m_{2}, v_{1}, v_{2}\right)+Z_{1},
$$

where $g_{P S}\left(\theta, m_{1}, m_{2}, v_{1}, v_{2}\right) \equiv \frac{\left[\left(m_{1}+m_{2}\right) v_{2}\right]^{2}}{2\left(\theta+m_{1}+m_{2}\right)}$. We have that $g_{P S}\left(\theta, m_{1}, m_{2}, v_{1}, v_{2}\right)>g_{N P}\left(\theta, m_{1}, m_{2}, v_{1}, v_{2}\right)$ if $v_{2}=v_{1}$. Also, $g_{N P}\left(\theta, m_{1}, m_{2}, v_{1}, v_{2}\right)-g_{P S}\left(\theta, m_{1}, m_{2}, v_{1}, v_{2}\right)=\frac{m_{1}^{2} m_{2} v_{1}^{2}\left(\theta m_{1}^{2}-\theta^{2} m_{2}+m_{1} m_{2}^{2}+m_{2}^{3}\right)}{2\left(\theta+m_{1}\right)\left(m_{1}+m_{2}\right)^{2}\left(\theta+m_{2}\right)\left(\theta+m_{1}+m_{2}\right)}$ if $v_{2}=\frac{m_{1}}{m_{1}+m_{2}} v_{1}$, which takes a positive value if and only if $\theta<\frac{m_{1}^{2}+\sqrt{m_{1}^{4}+4 m_{1} m_{2}^{3}+4 m_{2}^{4}}}{2 m_{2}}$. Furthermore, it can be shown that $\frac{\partial}{\partial v_{2}}\left(g_{P S}\left(\theta, m_{1}, m_{2}, v_{1}, v_{2}\right)-g_{N P}\left(\theta, m_{1}, m_{2}, v_{1}, v_{2}\right)\right)>0$. This implies that there exists a unique value $v_{2}^{\prime}, \frac{m_{1}}{m_{1}+m_{2}} v_{1} \leq v_{2}^{\prime}<v_{1}$, such that $\pi_{P S}\left(\hat{x}_{C}^{*}\right)>$ $\pi_{H}\left(\hat{x}_{H}^{*}, \hat{x}_{L}^{*}\right)+\pi_{L}\left(\hat{x}_{H}^{*}, \hat{x}_{L}^{*}\right)$ if $v_{2}>v_{2}^{\prime}$ while $\pi_{P S}\left(\hat{x}_{C}^{*}\right)<\pi_{H}\left(\hat{x}_{H}^{*}, \hat{x}_{L}^{*}\right)+\pi_{L}\left(\hat{x}_{H}^{*}, \hat{x}_{L}^{*}\right)$ if $v_{2}<v_{2}^{\prime}$, where $\frac{m_{1}}{m_{1}+m_{2}} v_{1}<v_{2}^{\prime}$ holds if and only if $\theta<\frac{m_{1}^{2}+\sqrt{m_{1}^{4}+4 m_{1} m_{2}^{3}+4 m_{2}^{4}}}{2 m_{2}}$. Q.E.D.

Proof of Proposition 9: First note that each type 2 consumer's surplus is zero in the equilibrium of both subgames. Each type 1 consumer's surplus is $\left(v_{1}-v_{2}\right) Q_{L}\left(\hat{x}_{C}^{*}\right)\left(\left(v_{1}-\right.\right.$ 
$\left.\left.v_{2}\right) Q_{L}\left(\hat{x}_{L}^{*}\right)\right)$ in the equilibrium of platform sharing (non-platform sharing) subgame, where $\hat{x}_{C}^{*}=\frac{m_{1}+m_{2}}{\theta+m_{1}+m_{2}} v_{2}>\hat{x}_{L}^{*}=\frac{m_{2}}{\theta+m_{2}} v_{2}$ implies $\left(v_{1}-v_{2}\right) Q_{L}\left(\hat{x}_{C}^{*}\right)>\left(v_{1}-v_{2}\right) Q_{L}\left(\hat{x}_{L}^{*}\right)$. Regarding the total surplus, given $T S_{P S}=\pi_{P S}\left(\hat{x}_{C}^{*}\right)+m_{1}\left(v_{1}-v_{2}\right) Q_{L}\left(\hat{x}_{C}^{*}\right) \equiv T S_{P S}\left(\hat{x}_{C}^{*}\right)$ and $T S_{N P}=$ $\pi_{H}\left(\hat{x}_{H}^{*}, \hat{x}_{L}^{*}\right)+\pi_{L}\left(\hat{x}_{H}^{*}, \hat{x}_{L}^{*}\right)+m_{1}\left(v_{1}-v_{2}\right) Q_{L}\left(\hat{x}_{L}^{*}\right) \equiv T S_{N P}\left(\hat{x}_{H}^{*}, \hat{x}_{L}^{*}\right)$, we find that $\frac{\partial}{\partial v_{2}}\left(T S_{P S}-\right.$ $\left.T S_{N P}\right)=\frac{m_{1}\left[\theta m_{2} v_{1}+\left(v_{1}-v_{2}\right)\left(m_{2}^{2}+\theta m_{1}+m_{1} m_{2}\right)\right]}{\left(\theta+m_{1}+m_{2}\right)\left(\theta+m_{2}\right)}>0$ for all $v_{2} \in\left(\frac{m_{1}}{m_{1}+m_{2}} v_{1}, v_{1}\right)$. Proposition 8 and 9(i) then imply 9 (ii). Q.E.D.

Proof of Proposition 10: We have that $\pi_{N P}\left(x_{H}^{*}, x_{L}^{*}\right)-\left[\pi_{H}\left(\hat{x}_{H}^{*}, \hat{x}_{L}^{*}\right)+\pi_{L}\left(\hat{x}_{H}^{*}, \hat{x}_{L}^{*}\right)\right]=$ $\frac{\left[m_{1}\left(v_{1}-v_{2}\right)^{2}\right]}{2\left(\theta+m_{2}\right)}>0$. Given the definitions of $\bar{v}_{2}$ and $\tilde{v}_{2}$, this implies $\bar{v}_{2}<\tilde{v}_{2}$. Q.E.D.

Proof of Proposition 11: Suppose $v_{2}>\tilde{v}_{2}$. Then Proposition 10 implies that a platform is shared in the equilibrium of the monopoly case as well as the duopoly case. Propositions 6 and 8 then imply (i).

Next suppose $v_{2}<\bar{v}_{2}$. Then a platform is not shared in the equilibrium of the monopoly case as well as the duopoly case. In the equilibrium of the monopoly case, (a) each type 1 consumer's surplus is $\left(v_{1}-v_{2}\right) Q_{L}\left(x_{L}^{*}\right)$, (b) the monopolist's profit is $\pi_{N P}\left(x_{H}^{*}, x_{L}^{*}\right)$, and (c) the total surplus is $T S_{N P}\left(x_{H}^{*}, x_{L}^{*}\right)$. In the equilibrium of the duopoly case, (a) each type 1 consumer's surplus is $\left(v_{1}-v_{2}\right) Q_{L}\left(\hat{x}_{L}^{*}\right)$, (b) the joint profit of firms $H$ and $L$ is $\pi_{H}\left(\hat{x}_{H}^{*}, \hat{x}_{L}^{*}\right)+\pi_{L}\left(\hat{x}_{H}^{*}, \hat{x}_{L}^{*}\right)$, and (c) the total surplus is $T S_{N P}\left(\hat{x}_{H}^{*}, \hat{x}_{L}^{*}\right)$. We have that $\left(v_{1}-\right.$ $\left.v_{2}\right) Q_{L}\left(x_{L}^{*}\right)<\left(v_{1}-v_{2}\right) Q_{L}\left(\hat{x}_{L}^{*}\right)$ and $\pi_{N P}\left(x_{H}^{*}, x_{L}^{*}\right)>\pi_{H}\left(\hat{x}_{H}^{*}, \hat{x}_{L}^{*}\right)+\pi_{L}\left(\hat{x}_{H}^{*}, \hat{x}_{L}^{*}\right)$. Also, given that $\left(x_{H}, x_{L}\right)=\left(\hat{x}_{H}^{*}, \hat{x}_{L}^{*}\right)$ maximizes the value of $T S_{N P}\left(x_{H}, x_{L}\right)$, we have that $T S_{N P}\left(x_{H}^{*}, x_{L}^{*}\right)<$ $T S_{N P}\left(\hat{x}_{H}^{*}, \hat{x}_{L}^{*}\right)$.

Finally, suppose $\bar{v}_{2}<v_{2}<\tilde{v}_{2}$. Then a platform is shared in the equilibrium of the duopoly case but not shared in the equilibrium of the monopoly case. In the equilibrium of the monopoly case, (a) each type 1 consumer's surplus is $\left(v_{1}-v_{2}\right) Q_{L}\left(x_{L}^{*}\right)$, (b) the monopolist's profit is $\pi_{N P}\left(x_{H}^{*}, x_{L}^{*}\right)$, and (c) the total surplus is $T S_{N P}\left(x_{H}^{*}, x_{L}^{*}\right)$. In the equilibrium of the duopoly case, (a) each type 1 consumer's surplus is $\left(v_{1}-v_{2}\right) Q_{L}\left(\hat{x}_{C}^{*}\right)$, (b) the joint profit of firms $H$ and $L$ is $\pi_{P S}\left(\hat{x}_{C}^{*}\right)$, and (c) the total surplus is $T S_{P S}\left(\hat{x}_{C}^{*}\right)$. We have that $\left(v_{1}-v_{2}\right) Q_{L}\left(x_{L}^{*}\right)<\left(v_{1}-v_{2}\right) Q_{L}\left(\hat{x}_{C}^{*}\right)$, and $\pi_{N P}\left(x_{H}^{*}, x_{L}^{*}\right)>\pi_{P S}\left(\hat{x}_{C}^{*}\right)$. Also, given Proposition 9 we have that $T S_{P S}\left(\hat{x}_{C}^{*}\right)>T S_{N P}\left(\hat{x}_{H}^{*}, \hat{x}_{L}^{*}\right)>T S_{N P}\left(x_{H}^{*}, x_{L}^{*}\right)$. This completes the proof. Q.E.D. 


\section{References}

Anonymous, 2006, "Vehicle profiles: A user's guide", Consumer Reports, 71, April, pp. 39-78.

Bremner, B., G. Edmondson, and C. Dawson, 2004, "Nissan's boss", Business Week, October 4, pp. 50 .

Choi, J.P., 1993, "Cooperative R\&D with product market competition", International Journal of Industrial Organization, 11, pp. 553-571.

d'Aspremont, C. and A. Jacquemin, 1988, "Cooperative and noncooperative R\&D in duopoly with spillovers", American Economic Review, 78, pp. 1133-1137.

Dixit, A.K., 1979, "A model of duopoly suggesting a theory of entry barriers", Bell Journal of Economics, 10, pp. 20-32.

Ghosh, A. and H. Morita, 2006, "Platform sharing in a differentiated duopoly", Journal of Economics and Management Strategy, 15, pp. 397-429.

Katz, M.L., 1986, "An analysis of cooperative research and development", RAND Journal of Economics, 17, pp. 527-543.

Kamien, I.M., E. Muller, and I. Zang, 1992, "Research joint venture and R\&D cartels", American Economic Review, 82, pp. 1293-1306.

Krishnan, V. and G. Gupta, 2001, "Appropriateness and impact of platform-based product development", Management Science, 47, pp. 52-68.

Lambertini, L., S. Poddar and D. Sasaki, 2002, "Research joint ventures, product differentiation, and price collusion", International Journal of Industrial Organization, 20, pp. 829-854.

Lambertini, L., S. Poddar and D. Sasaki, 2003, "RJVs in product innovation and cartel stability", Review of Economic Design, 7, pp. 465-477.

Lin, P. and K. Saggi, 2002, "Product differentiation, process R\&D, and the nature of market competition", European Economic Review, 46, pp. 201-211.

Meyer, M.H. and A.P. Lehnerd, 1997, The power of product platforms, The Free Press: New York.

Motta, M., 1992, "Cooperative R\&D and vertical product differentiation", International Journal of Industrial Organization, 10, pp. 643-661. 
Mussa, M. and S. Rosen, 1978, "Monopoly and product quality", Journal of Economic Theory, 18, pp. 301-17.

Nobeoka, K. and M.A. Cusumano, 1997, "Multiproject strategy and sales growth: The benefits of rapid design transfer in new product development", Strategic Management Journal, 18, pp. 169-186.

Rechtin, M. and R. Kranz, 2003, "Japanese step up product charge", Automotive News, 77, August 18, pp. 26-30.

Robertson, D. and K. Ulrich, 1998, "Planning for product platforms", Sloan Management Review, pp. 19-31.

Singh, N. and X. Vives, 1984, "Price and quantity competition in a differentiated duopoly", RAND Journal of Economics, 15, pp. 546-554.

Suzumura, K., 1992, "Cooperative and noncooperative R\&D in an oligopoly with spillovers", American Economic Review, 82, pp. 1307-1320.

Szczesny, J., 2003, Mazda3 ushers in new Ford era: Platform sharing across global brands is Ford's new way of doing business. Viewed February 142006 ,

$<$ http://www.thecarconnection.com/index.asp?article $=6574 \mathrm{pf}=1>$.

Tierney, C., A. Bawden, and M. Kunii, 2000, "Dynamic duo", Business Week, October 23, pp. 26.

Waldman, M., 1996, "Durable goods pricing when quality matters", Journal of Business, 69, pp. 489-510. 